\title{
Intensity of swimming exercise influences aortic reactivity in rats
}

\author{
A.F. Brito ${ }^{1,2,3}$, A.S. Silva ${ }^{3}$, I.L.L. Souza ${ }^{1,2}$, J.C. Pereira ${ }^{1,2}$ and B.A. da Silva ${ }^{1,2}$ \\ ${ }^{1}$ Programa de Pós-Graduação em Produtos Naturais e Sintéticos Bioativos, Centro de Ciências da Saúde, \\ Universidade Federal da Paraíba, Paraíba, Brasi \\ ${ }^{2}$ Laboratório de Farmacologia Funcional Professor George Thomas, Centro de Ciências da Saúde, \\ Universidade Federal da Paraíba, Paraíba, Brasil \\ ${ }^{3}$ Laboratório de Estudos do Treinamento Físico Aplicado ao Desempenho e Saúde, Departamento de Educação Física, \\ Centro de Ciências da Saúde, Universidade Federal da Paraíba, Paraíba, Brasil
}

\begin{abstract}
Exercise is known to cause a vasodilatory response; however, the correlation between the vasorelaxant response and different training intensities has not been investigated. Therefore, this study evaluated the vascular reactivity and lipid peroxidation after different intensities of swimming exercise in rats. Male Wistar rats (aged 8 weeks; $250-300 \mathrm{~g}$ ) underwent forced swimming for $1 \mathrm{~h}$ whilst tied to loads of 3, 4, 5, 6, and 8\% of their body weight, respectively (groups G3, G4, G5, G6 and G8, respectively; n=5 each). Immediately after the test, the aorta was removed and suspended in an organ bath. Cumulative relaxation in response to acetylcholine $\left(10^{-12}-10^{-4} \mathrm{M}\right)$ and contraction in response to phenylephrine $\left(10^{-12}-10^{-5} \mathrm{M}\right)$ were measured. Oxidative stress was estimated by determining malondialdehyde concentration. The percentages of aorta relaxation were significantly higher in G3 $(7.9 \pm 0.20)$, G4 $(7.8 \pm 0.29)$, and G5 $(7.9 \pm 0.21)$, compared to the control group $(7.2 \pm 0.04)$, while relaxation in the $\mathrm{G} 6$ $(7.4 \pm 0.25)$ and $G 8(7.0 \pm 0.06)$ groups was similar to the control group. In contrast, the percentage of contraction was significantly higher in G6 (8.8 \pm 0.1$)$ and G8 (9.7 \pm 0.29$)$ compared to the control $(7.1 \pm 0.1), G 3(7.3 \pm 0.2), G 4(7.2 \pm 0.1)$ and G5 $(7.2 \pm 0.2 \%)$ groups. Lipid peroxidation levels in the aorta were similar to control levels in G3, G4 and G5, but higher in G6 and G8, and significantly higher in G8 (one-way ANOVA). These results indicate a reduction in vasorelaxing activity and an increase in contractile activity in rat aortas after high-intensity exercise, followed by an increase in lipid peroxidation.
\end{abstract}

Key words: Aerobic exercise; Anaerobic exercise; Lipid peroxidation; Smooth muscle; Swimming; Vessel

\section{Introduction}

Improvements in vasomotor function are one of the many benefits associated with aerobic exercise. This involves an increase in endothelium-dependent vasodilation and an attenuation of the vasoconstrictor response, as observed in healthy animals (1-3), models of hypertension $(4)$ and in humans $(5,6)$.

Bechara et al. (7) showed that improvements in the vasodilator response occurred immediately after a single exercise session performed on a treadmill at $60 \%$ of maximal exercise capacity, directly related to an increase in the bioavailability of endothelial nitric oxide and attenuation of the maximal contractile response $(8,9)$. This postexercise response model is relevant to the development of post-exercise hypotension in humans, in which both hypertensive and normotensive subjects experience a reduction in blood pressure during the first minute after a single exercise session (10-12), which may continue for hours after the exercise session (13). This post-exercise hypotension may be partly explained by a transient increase in vasodilator activity (14).

Post-exercise hypotension is more evident following moderate-intensity exercise $\left(60-70 \%\right.$ of $\left.\dot{\mathrm{VO}}_{2} \max \right)(15)$, though even mild exercise has been reported to promote post-exercise hypotension $(16,17)$. In contrast, high-intensity exercise has been reported to eliminate the hypotensive effect or even promote increased blood pressure $(16,18)$. The mechanisms responsible for these changes in blood pressure in response to highintensity exercise have been investigated and include roles for sympathetic activity (10), increased angiotensinconverting enzyme (19), and oxidative stress (20). However, no studies have yet determined if vascular reactivity is involved in the differential blood pressure response to exercise intensity.

We hypothesized that high-intensity exercise might result in a smaller relaxant response and greater contractile

Correspondence: A.F. Brito: <alineebrito@gmail.com>.

Received September 25, 2014. Accepted January 16, 2015. First published online September 18, 2015. 
response in Wistar rats. Therefore, we evaluated the relaxation and contraction responses of the aorta in Wistar rats immediately after different intensities of swimming exercise and investigated the possible role of exerciseinduced lipid peroxidation in these responses.

\section{Material and Methods}

\section{Animals \\ Male Wistar rats (aged 8 weeks; 250-300 g) were obtained from the vivarium Prof. Thomas George (Centro de Biotecnologia, Universidade Federal da Paraíba). The animals were kept in ventilated cages with a balanced diet of feed pellets (Labina ${ }^{\mathbb{R}}$, Purina - Paulínia, Brasil) with access to water ad libitum, at constant temperature $\left(21 \pm 1^{\circ} \mathrm{C}\right)$, and a daily $12-\mathrm{h}$ light-dark cycle. The exercise tests were performed from 8-9 am and the cumulative concentration-response curves were obtained from $9 \mathrm{am}-10 \mathrm{pm}$. This study was performed in accordance with the Guide for the Care and Use of Laboratory Animals (1996). The study protocol was approved by the Ethics Committee for Animal Use of the Centro de Biotecnologia from the Universidade Federal da Paraíba (protocol \#1101/11).}

\section{Drugs and chemicals}

Calcium chloride dihydrate $\left(\mathrm{CaCl}_{2} \cdot 2 \mathrm{H}_{2} \mathrm{O}\right)$, magnesium chloride hexahydrate $\left(\mathrm{MgCl}_{2} \cdot 6 \mathrm{H}_{2} \mathrm{O}\right)$, potassium chloride $(\mathrm{KCl})$, and sodium bicarbonate $\left(\mathrm{NaHCO}_{3}\right)$ were purchased from VETEC (Brazil). Monosodium phosphate 1-hydrate $\left(\mathrm{NaH}_{2} \mathrm{PO}_{4} \cdot \mathrm{H}_{2} \mathrm{O}\right)$, glucose $\left(\mathrm{C}_{6} \mathrm{H}_{12} \mathrm{O}_{6}\right)$, magnesium sulfate monohydrate $\left(\mathrm{MgSO}_{4} \cdot \mathrm{H}_{2} \mathrm{O}\right)$, and hydrochloric acid ( $\mathrm{HCl} \mathrm{PA)} \mathrm{were} \mathrm{purchased} \mathrm{from} \mathrm{Nuclear}$ (Brazil). Sodium chloride $(\mathrm{NaCl})$ was purchased from Dinâmica (Brazil). Carbamylcholine chloride, acetylcholine (ACh), and phenylephrine (Phe) were purchased from Sigma-Aldrich (USA). The carbogenic mixture $\left(\begin{array}{llll}95 \% & \mathrm{O}_{2} \text { and } 5 \% & \mathrm{CO}_{2}\end{array}\right)$ was purchased from White Martins (Brazil).

\section{Equipment}

Organ baths $(5 \mathrm{~mL})$ were heated to the appropriate temperature using thermostatic pumps (Fisatom 597; Fisatom, Brazil, and Polystat 12002; Cole-Parmer, USA), connected to a force transducer (TIM-50). These were connected to an amplifier (AECAD04F; both AVS Projetos, Brazil), which in turn was connected to a plate/D converter installed on a microcomputer with the AQCAD program version 8.0.5 (ANCAD version 5.33, Brazil).

\section{Exercise program}

The animals were randomly divided into 6 groups of 5 rats each. Rats in the exercise groups were submitted to swimming sessions at five different exercise intensities (G3, G4, G5, G6 and G8) (see below) for $60 \mathrm{~min}$, respectively. Rats in the control group (CG) were maintained under the same conditions as the exercised animals and were acclimatized on the experiment day, but did not perform the swimming tests.

According to Gobatto et al. (21), control rats were maintained in shallow clean water at $31 \pm 1^{\circ} \mathrm{C}$ throughout the entire experimental period and were euthanized at the end of the experiment.

Behaviors, including the tendency to adopt passive strategies ('immobilization time') represented by sitting at the bottom of the tank, standing immobile on the bottom of the tank, floating, or carrying out small movements to keep their head above water, were observed by a trained researcher. Animals underwent two adaptation sessions 1 week before the experimental protocol, with an interval of $48 \mathrm{~h}$ between them, to minimize stress. The rats were put into the swimming tank for $30 \mathrm{~min}$, with no additional load (22). Their behavior was analyzed during the first $15 \mathrm{~min}$, which was the duration recorded in the forced swimming tests (23). Animals that failed to behave within 15 min were excluded, while animals that performed behaviors within this period were randomized among the exercise groups.

The swimming protocol was adapted from Chies et al. (1). We used a rectangular polyethylene tank $(120-\mathrm{cm}$ long $\times$ $50-\mathrm{cm}$ deep $\times 43-\mathrm{cm}$ wide) with water at $29 \pm 1^{\circ} \mathrm{C}$. The rats were submitted to swimming exercise for a period of $60 \mathrm{~min}$, with a metal ring attached to their chest by an elastic ribbon $1-\mathrm{cm}$ wide. The ribbon was adjusted to fit the animal to prevent discomfort or stress and to avoid limiting the animal's movement during exercise. If the ribbon became displaced, the researcher paused the experiment, adjusted the ribbon, and then resumed the exercise test. The metal rings in groups G3, G4, G5, G6 and G8 represented 3, 4, 5,6 , and $8 \%$ of the animal's body weight, respectively, corresponding to a range of exercise intensities. The increase from $6 \%$ to $8 \%$ was based on the premise proposed by Gobatto et al. (21), who showed that, in rats submitted to different intensities of swimming exercise, $6 \%$ load corresponded to the maximal lactate steady state, while $8 \%$ represented higher exercise intensity. This study therefore compared intensities below the anaerobic threshold ( $3 \%$ and $4 \%$ ), around the anaerobic threshold (5\% and $6 \%$ ), and above the threshold ( $8 \%)$.

\section{Assessment of exercise-induced lactate}

Immediately at the end of the exercise sessions, $25 \mu \mathrm{L}$ of arterial blood were withdrawn from the tail vein into calibrated heparinized capillaries. The samples were then placed in Eppendorf tubes containing $400 \mu \mathrm{L} 4 \%$ trichloroacetic acid and refrigerated until analysis. Serum lactate levels were analyzed according to the protocol proposed by Engel and Jones (24).

\section{Organ preparation and aorta responsiveness}

Five minutes after the end of exercise, rats were euthanized by cervical dislocation. Thoracic aortic rings 3-5 mm long were obtained free of connective tissue. The isometric response was determined by suspending 
individual rings by a stainless steel strap in organ baths $(5 \mathrm{~mL})$ containing Krebs solution (118.0 mM NaCl, $4.6 \mathrm{mM} \mathrm{KCl}, 5.7 \mathrm{mM} \mathrm{MgSO}$, $1.1 \mathrm{mM} \mathrm{KH}_{2} \mathrm{PO}_{4}, 2.5 \mathrm{mM}$ $\mathrm{CaCl}_{2}, 11.0 \mathrm{mM}$ glucose; $25.0 \mathrm{mM} \mathrm{NaHCO}_{3}$ ), adjusted to $\mathrm{pH} 7.4$ and maintained at $37^{\circ} \mathrm{C}$. The preparations were stabilized for $1 \mathrm{~h}$ under a resting tension of $1 \mathrm{~g}$, and aerated with a mixture of $95 \% \mathrm{O}_{2}$ and $5 \% \mathrm{CO}_{2}$.

After the stabilization period, isometric contraction was induced by Phe $3 \times 10^{-7} \mathrm{M}$. During the tonic phase of the contraction, Ach $10^{-6} \mathrm{M}$ was added to verify the integrity of the endothelium (25). The vascular endothelium was considered complete when the aortic rings showed relaxation $\geqslant 50 \%(26)$, and non-functional if relaxation was $\leqslant 10 \%$. After washing, the tonic component of a second reaction was induced by Phe $3 \times 10^{-7} \mathrm{M}$ for $30 \mathrm{~min}$, followed by the cumulative addition of $\mathrm{ACh}$ to the organ baths $\left(10^{-12}-10^{-4} \mathrm{M}\right)$ to induce relaxation.

For pharmacological evaluation of contractile vascular reactivity, the aorta was stabilized for $60 \mathrm{~min}$ and checked for the presence or absence of functional endothelium, as described above. A cumulative curve was then obtained by adding increasing concentrations of Phe $\left(10^{-12}-10^{-5} \mathrm{M}\right)$ to the organ bath. Aorta responsiveness was evaluated by comparing $\mathrm{pD}_{2}$ (negative logarithm of molar concentration of an agonist that produces $50 \%$ of its maximal effect) and $E_{\max }$ (maximum effect) values for the control and trained groups.

\section{Exercise-induced oxidative stress in the aorta and heart}

The rates of lipid peroxidation in the aorta and heart were estimated by determining malondialdehyde (MDA), using the thiobarbituric acid test. Tissues were washed with cold saline to minimize interference of hemoglobin with free radicals and to remove adhered blood. They were then weighed and homogenized with $\mathrm{KCl} 10 \%$, $250 \mu \mathrm{L}$ was removed and warmed in a water bath at $37^{\circ} \mathrm{C}$ for $1 \mathrm{~h}$, and $400 \mu \mathrm{L}$ of perchloric acid $35 \%$ was added and centrifuged at $0.02 \mathrm{~g}$ for $20 \mathrm{~min}$ at $4^{\circ} \mathrm{C}$. The supernatant was removed and placed in contact with $400 \mu \mathrm{L}$ of thiobarbituric acid $0.6 \%$ and the mixture was incubated at $95-100^{\circ} \mathrm{C}$ for $1 \mathrm{~h}$. After cooling, the absorbance of the supernatant was read at $532 \mathrm{~nm}$. A standard curve was generated using 1,1,3,3-tetrametoxipropane. The results are reported as nmol MDA/mg protein. Protein concentration was measured using the Bradford method (27). The MDA concentration in each tissue sample was replaced by the absorbance values of the MDA standard curve obtained from different concentrations of a standard solution. The data were normalized by the dry weight in a given volume of the sample, where the absorbance values were divided by the weight in grams of the tissue.

\section{Statistical analysis}

Data are reported as means \pm SE and were tested for normality and homogeneity using the Shapiro-Wilk and
Levine tests, respectively. Comparisons between groups were made using one-way ANOVA, with post hoc Bonferroni's test. Values of $\mathrm{P}<0.05$ were considered to be significant. The values of $\mathrm{pD}_{2}$ and $\mathrm{E}_{\max }$ were calculated by non-linear regression. All results were analyzed using GraphPad Prism version 5.01 (GraphPad Software Inc., USA).

\section{Results}

\section{Assessment of exercise-induced lactate}

Lactate content increased in proportion to the exercise intensity. There was no significant difference in lactate production between $\mathrm{G} 3(2.8 \pm 0.35 \mathrm{mM})$ and $\mathrm{G} 4$ (3.35 $\pm 0.80 \mathrm{mM}$ ), but lactate production increased significantly with subsequent increases in exercise intensity: G5 > G4 (4.54 \pm 0.39 vs $3.35 \pm 0.80 \mathrm{mM}, \mathrm{P}<0.05) ; \mathrm{G} 6>\mathrm{G} 5$ (5.66 \pm 0.39 vs $4.54 \pm 0.39 \mathrm{mM}, \mathrm{P}<0.05)$; and $\mathrm{G} 8>\mathrm{G} 6(6.59$ \pm 0.42 vs $5.66 \pm 0.39 \mathrm{mM}, \mathrm{P}<0.05$ ) (Figure 1).

\section{Pharmacological evaluation of rat aorta responsiveness}

Aorta relaxation was significantly greater in G3, G4 and $\mathrm{G} 5$ compared to the $\mathrm{CG}$ (Figure $2 \mathrm{~A}$ and $\mathrm{B}$ ), as demonstrated by the values of $\mathrm{pD}_{2} \quad(\mathrm{G} 3=7.9 \pm 0.20$, $\mathrm{G} 4=7.8 \pm 0.29, \mathrm{G} 5=7.9 \pm 0.21, \mathrm{CG}=7.2 \pm 0.04, \mathrm{P}<0.05)$. Conversely, aorta relaxation was similar to the control level in $\mathrm{G} 6$ and $\mathrm{G} 8$ ( $\mathrm{G} 6=7.4 \pm 0.25, \mathrm{G} 8=7.0 \pm 0.06$ ) (Figure 2C and D). G8 showed reduced responsiveness compared to G3, G4 and G5.

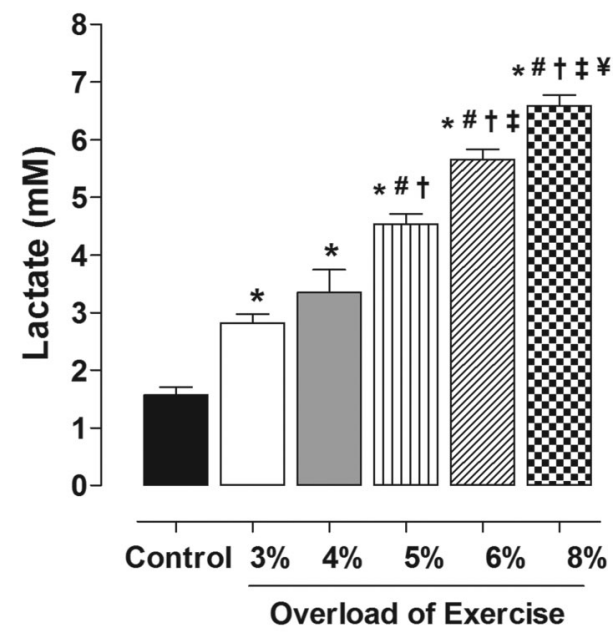

Figure 1. Lactate production as a function of exercise intensity. Data are reported as means $\pm S E$ ( $n=5$ per group). Exercise intensity was based on loading with $3,4,5,6$ and $8 \%$ of body weight, respectively, during swimming exercise. ${ }^{*} \mathrm{P}<0.05$ vs control; ${ }^{\#} \mathrm{P}<0.05$ vs $3 \% ;{ }^{+} \mathrm{P}<0.05$ vs $4 \%$; ${ }^{*} \mathrm{P}<0.05$ vs $5 \%$; ${ }^{¥} \mathrm{P}<0.05$ vs $6 \%$ (one-way ANOVA). 
A
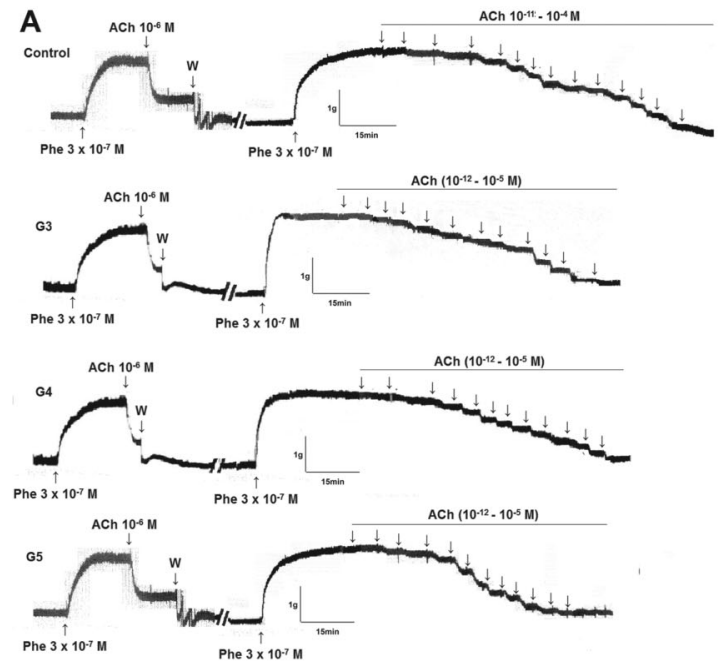

C

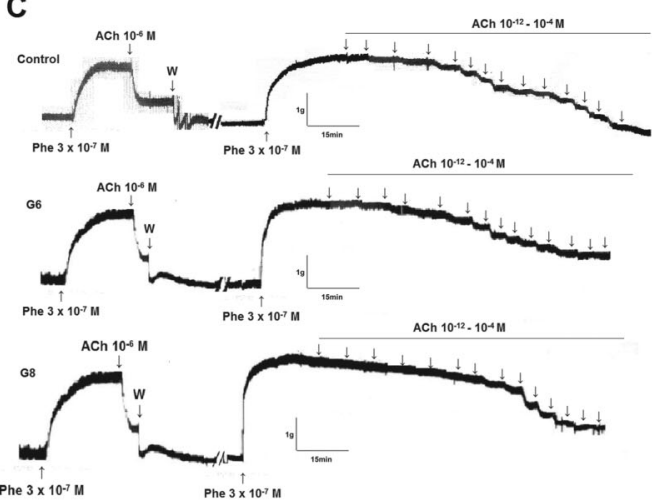

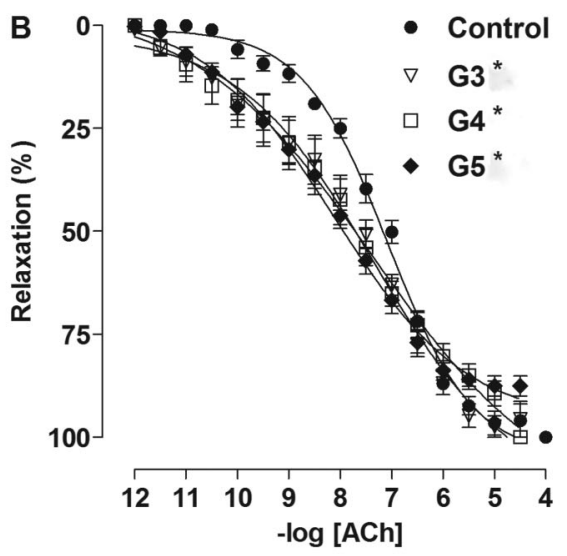

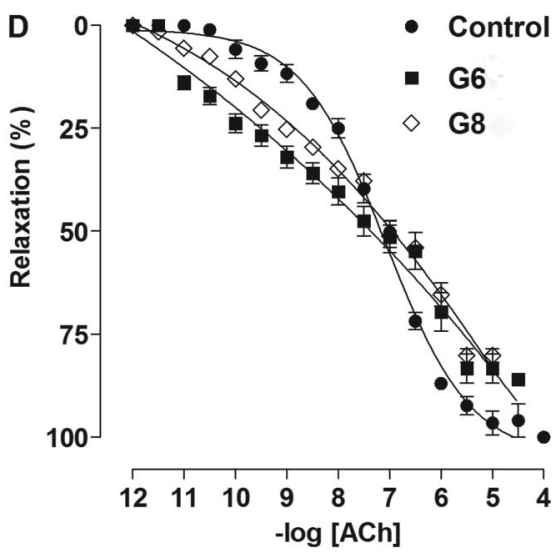

Figure 2. Representative traces and relaxant effect on rat aorta induced by acetylcholine in control, $G 3 \mathrm{G} 4$, and $\mathrm{G} 5$ ( $A$ and $B$, lower intensities), and $\mathrm{G} 6$ and $\mathrm{G} 8$ ( $C$ and $D$, higher intensities) groups. Data are reported as means $\pm \mathrm{SE}$ ( $\mathrm{n}=5$ per group). G3, G4, G5, G6 and G8: exercise intensity based on loading with $3,4,5,6$ and $8 \%$ of body weight, respectively, during swimming exercise. ${ }^{*} P<0.05$ vs control (one-way ANOVA). Phe: phenylephrine; W: wash.

$\mathrm{E}_{\max }(\%)$ was significantly reduced in $\mathrm{G} 6$ and $\mathrm{G} 8 \mathrm{com}-$ pared to CG, G3, G4 and G5: $C G=99 \pm 0.5 ; G 3=98 \pm 3$; $\mathrm{G} 4=99 \pm 0.2 ; \mathrm{G} 5=97 \pm 0.84$ vs $\mathrm{G} 6=83 \pm 4$ and $\mathrm{G} 8=80 \pm 2$ $(\mathrm{P}<0.05)$.

The percentage of contraction of the aorta in response to exercise of different intensities varied. The contractile response to Phe was similar in G3, G4, G5 and CG (Figure $3 \mathrm{~A}$ and $\mathrm{B}$ ), but contraction at lower concentrations of Phe was significantly increased in G6 and G8 compared to CG, G3, G4, and $\mathrm{G} 5$ as demonstrated by $\mathrm{pD}_{2}$ : $\mathrm{CG}=7.1 \pm 0.1 ; \mathrm{G} 3=7.3 \pm 0.2 ; \mathrm{G} 4=7.2 \pm 0.1 ; \mathrm{G} 5=7.2$ \pm 0.2 vs $\mathrm{G} 6=8.8 \pm 0.1 ; \mathrm{G} 8=9.7 \pm 0.29(\mathrm{P}<0.05)$. Furthermore, the aorta contractile response was significantly higher in $\mathrm{G} 8$ rats compared to $\mathrm{G} 6$ rats $(9.7 \pm 0.29$ vs $8.8 \pm 0.1, P<0.05$ ) (Figure $3 C$ and $D$ ).

\section{Exercise-induced oxidative stress in aorta and heart}

All the exercise protocols increased lipid peroxidation compared to controls, irrespective of the exercise intensity. Exercise intensity promoted lipid peroxidation (Figure 4). Lipid peroxidation in the aorta was similar in G3, G4 and G5, but increased in G6, and further increased in G8. Peroxidation in the heart was similar in G3, G4, G5 and G6, but significantly higher in G8.

\section{Discussion}

The present study demonstrated that relatively low intensity swimming exercise (with a load of $3 \%, 4 \%$ or $5 \%$ of body weight) promoted acute vasorelaxant activity in the aorta without affecting its pattern of contraction. 
A Control

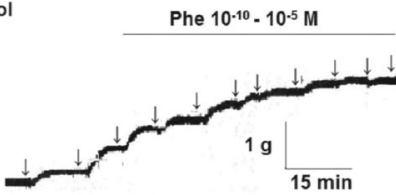

G3

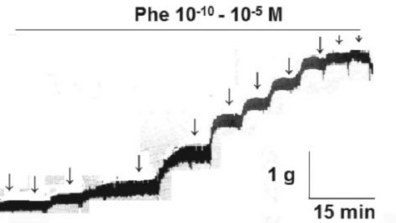

G4

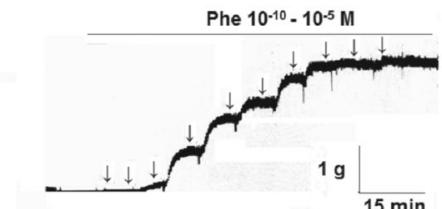

G5 Phe $10^{-10}-10^{-5} \mathrm{M}$

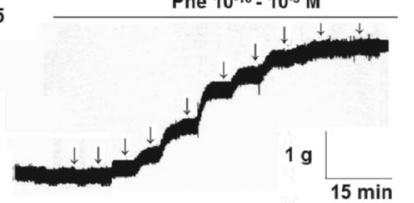

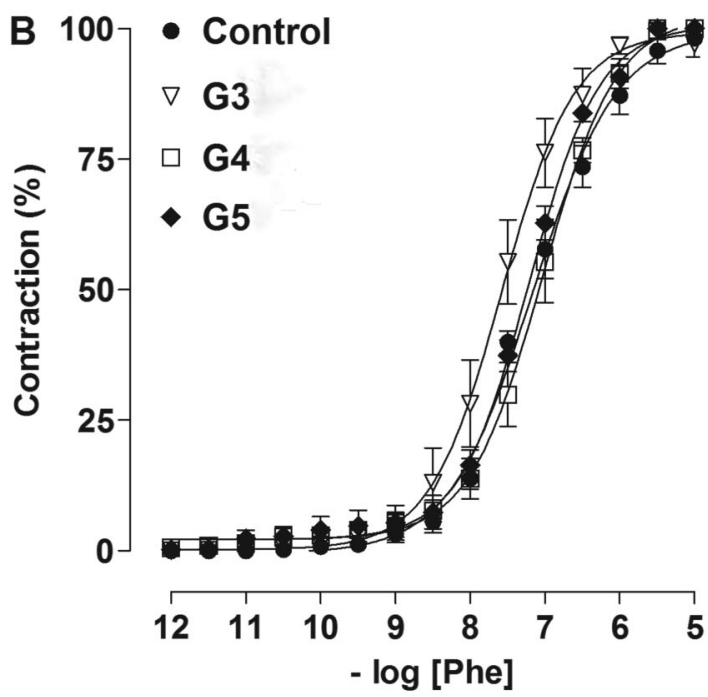
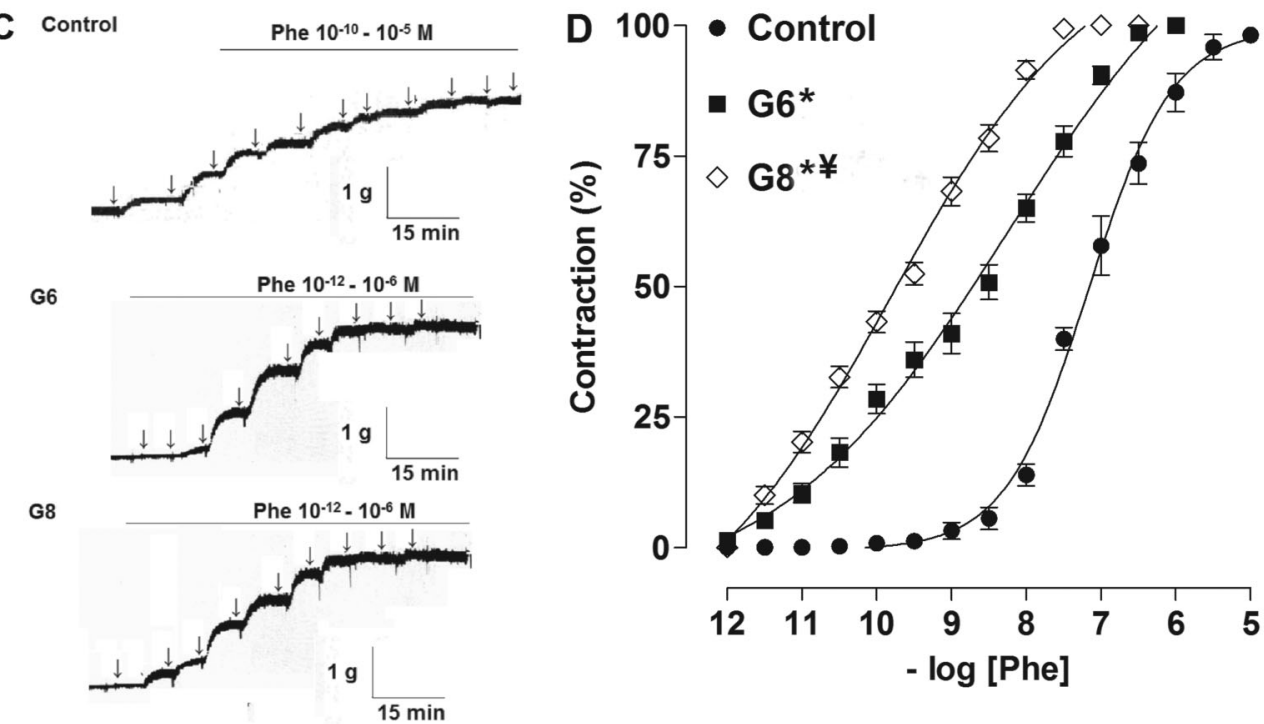

Figure 3. Representative traces and contractile response of rat aorta induced by phenylephrine in control, G3, G4, G5 ( $A$ and $B$, lower intensities), and $\mathrm{G} 6$ and $\mathrm{G} 8$ ( $C$ and $D$, higher intensities) groups. Data are reported as means $\pm \mathrm{SE}$ ( $\mathrm{n}=5$ per group). $\mathrm{G} 3, \mathrm{G} 4, \mathrm{G} 5, \mathrm{G} 6$ and G8: exercise intensity based on loading with $3,4,5,6$ and $8 \%$ of body weight, respectively, during swimming exercise. ${ }^{*} P<0.05 v s$ control; ${ }^{¥} \mathrm{P}<0.05$ vs G6 (one-way ANOVA). Phe: phenylephrine.

However, increased exercise intensity (load of $6 \%$ or $8 \%$ of body weight) reduced the relaxant effect of the exercise and increased the contractile response to Phe. The vascular response to loads of $6 \%$ or $8 \%$ was accompanied by a significant increase in lipid peroxidation.
We identified the metabolic demands of the exercise protocols by measuring lactate production, and noted that even the lowest intensity exercise increased lactacidemia. Exercise in the G3, G4 and G5 groups demonstrated aerobic characteristics, as proposed by Gobatto et al. (21) who identified lactate production of up to $5.5 \mathrm{mM}$ as 

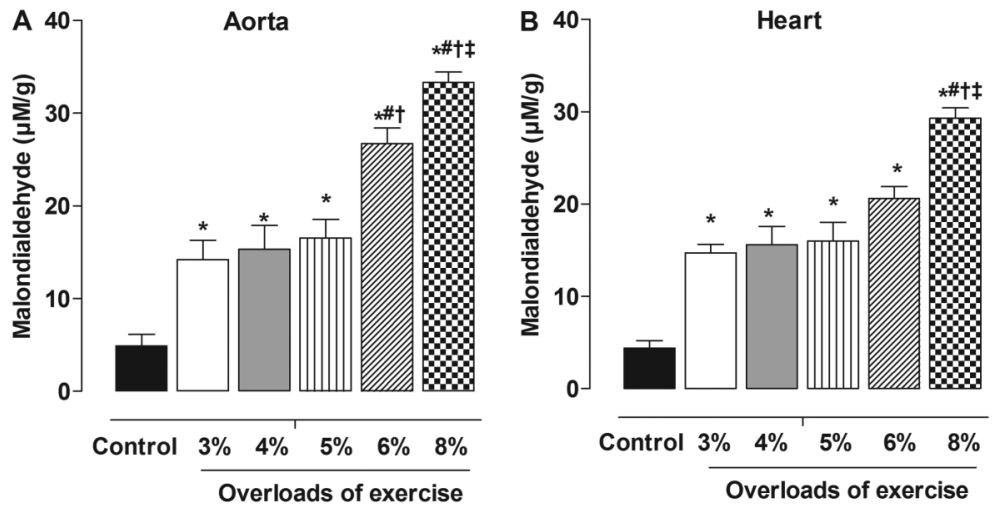

Figure 4. Levels of lipid peroxidation in aorta $(A)$ and heart $(B)$ in control group and groups with exercise intensity based on loading with $3,4,5,6$ and $8 \%$ of body weight, during swimming exercise. Data are reported as means \pm SE ( $\mathrm{n}=5$ per group). ${ }^{*} \mathrm{P}<0.05$ vs control; ${ }^{\#} \mathrm{P}<0.05$ vs $4 \% ;{ }^{+} \mathrm{P}<0.05$ vs $5 \% ;{ }^{+} \mathrm{P}<0.05$ vs $6 \%$ (one-way ANOVA). indicating aerobic predominance. However, our data differed slightly from those of Gobatto et al. (21), who reported that it was possible to exercise for about $30 \mathrm{~min}$ at the boundary between aerobic and anaerobic demands (equivalent to $5.5 \mathrm{mM}$ in rats). In our study, rats that swam for $60 \mathrm{~min}$ had $6.59 \mathrm{mM}$ lactate, which was incompatible with anaerobic activity. It is possible that our protocol merely reflected variations already reported in the literature. Carr et al. (28) reported an anaerobic threshold of $7 \mathrm{mM}$ in human athletes, whereas the general consensus is that the anaerobic threshold occurs at $4 \mathrm{mM}$. We, therefore, interpreted our results in terms of increasing exercise intensity.

Most studies investigating the influence of exercise on vascular reactivity in animal models have assessed responses to chronic training. However, recent studies have also examined the vasorelaxant response to acute exercise. These studies demonstrated that acute exercise improved the vasorelaxant response by increasing the influx of calcium and the release of nitric oxide $(29,30)$, and may also be mediated by insulin-like growth factors and by reduced superoxide production (31).

Vascular reactivity has been shown to differ between normotensive and hypertensive animals (4). Healthy animals in the exercise groups had $\mathrm{pD}_{2}$ values of about $7.60 \pm 0.11$, compared to $6.96 \pm 12.19$ in the control group. In hypertensive animals, ACh-induced relaxation produced $\mathrm{pD}_{2}$ values around $9.8 \pm 0.006$ in the exercise group, compared to $8.7 \pm 0.1$ in the control group.

Our results showed that the reduced relaxation associated with higher-intensity exercise (load of $6 \%$ or $8 \%$ ) was simultaneously accompanied by a significant increase in the contractile response. This increased vasoconstrictor response may be mediated by sympathetic stimulation. Jendzjowsky and Delorey (32) reported that high-intensity treadmill exercise significantly increased sympathetic stimulation in the rat femoral artery, resulting in a significant increase in the magnitude of vasoconstriction compared to moderate-intensity exercise. The greater the stimulation frequency, the greater increase in sympathetic activity.

Studies in humans demonstrated that this increase in sympathetic activity was responsible for changes in blood pressure during high-intensity exercise (33). However, it is difficult to investigate the mechanisms in detail in humans, and the current study provides valuable information to help explain the increase in blood pressure during high-intensity exercise through an increase in the vasoconstrictor response.

In addition to increased blood pressure caused by vasoconstriction, our hypothesis suggests that increased oxidative stress during high-intensity exercise (20) may also help to minimize blood pressure reduction after exercise. This was supported by the fact that vasoconstriction associated with high-intensity exercise was accompanied by increased MDA production. Increased vasoconstrictor activity is activated by a reduction in nitric oxide bioavailability as a result of increased ROS production through NADPH oxidase activity. This in turn is associated with local release of angiotensin II and vasoconstrictor prostanoids, which contribute to the increase in peripheral resistance, vascular damage caused by endothelial oxidative stress, and increased blood pressure (20).

Interestingly, previous studies have used progressive exercise protocols in which animals performed increasing intensities of exercise until they reached fatigue $(0.25-0.65 \mathrm{~m} / \mathrm{s})$. Although these protocols have been shown to be effective for observing differences in vascular reactivity in intense situations, they are less relevant to the situation in humans, where long-term, constant-intensity exercise protocols are adopted to prevent and treat cardiometabolic diseases. We, therefore, used an equivalent protocol in our current study. To the best of our knowledge, this study represents the first assessment of acute vascular reactivity responses in an animal model following a training protocol equivalent to that performed by humans.

In terms of exercise, moderate exercise is generally believed to be the most effective means of lowering blood pressure in humans, via reduced sympathetic activity, blood volume, and peripheral vascular resistance, and increased production of nitric oxide and peripheral blood flow. The results of the current study confirmed that vessels were more reactive to relaxing agents and less reactive to contractile agents in response to moderateintensity exercise, affirming the role of vascular reactivity 
in post-exercise hypotension. The results, therefore, confirmed that moderate exercise is the most suitable intensity for promoting vasodilation as a direct determinant of post-exercise hypotension. Previous data demonstrated the involvement of sympathetic nerve activity in the pressure response after exercise, while the results of the present study suggest that lipid peroxidation may also help to regulate the pressure response after exercise.

\section{References}

1. Chies $A B$, de Oliveira AM, Pereira FC, de Andrade CR, Correa FM. Phenylephrine-induced vasoconstriction of the rat superior mesenteric artery is decreased after repeated swimming. J Smooth Muscle Res 2004; 40: 249-258, doi: 10.1540/jsmr.40.249.

2. Delp MD, McAllister RM, Laughlin MH. Exercise training alters endothelium-dependent vasoreactivity of rat abdominal aorta. J Appl Physiol 1993; 75: 1354-1363.

3. Sun MW, Zhong MF, Gu J, Qian FL, Gu JZ, Chen H. Effects of different levels of exercise volume on endotheliumdependent vasodilation: roles of nitric oxide synthase and heme oxygenase. Hypertens Res 2008; 31: 805-816, doi: 10.1291/hypres.31.805.

4. Yang AL, Yeh CK, Su CT, Lo CW, Lin KL, Lee SD. Aerobic exercise acutely improves insulin- and insulin-like growth factor-1-mediated vasorelaxation in hypertensive rats. Exp Physiol 2010; 95: 622-629, doi: 10.1113/expphysiol. 2009.050146.

5. Goto C, Higashi Y, Kimura M, Noma K, Hara K, Nakagawa K, et al. Effect of different intensities of exercise on endothelium-dependent vasodilation in humans: role of endothelium-dependent nitric oxide and oxidative stress. Circulation 2003; 108: 530-535, doi: 10.1161/01.CIR.0000080893. 55729.28 .

6. Goto C, Nishioka K, Umemura T, Jitsuiki D, Sakagutchi A, Kawamura $M$, et al. Acute moderate-intensity exercise induces vasodilation through an increase in nitric oxide bioavailiability in humans. Am J Hypertens 2007; 20: 825-830.

7. Bechara LR, Tanaka LY, Santos AM, Jordao CP, Sousa LG, Bartholomeu $\mathrm{T}$, et al. A single bout of moderate-intensity exercise increases vascular NO bioavailability and attenuates adrenergic receptor-dependent and -independent vasoconstrictor response in rat aorta. J Smooth Muscle Res 2008; 44: 101-111, doi: 10.1540/jsmr.44.101.

8. Bertagnolli M, Schenkel PC, Campos C, Mostarda CT, Casarini DE, Bello-Klein A, et al. Exercise training reduces sympathetic modulation on cardiovascular system and cardiac oxidative stress in spontaneously hypertensive rats. Am J Hypertens 2008; 21: 1188-1193.

9. Rossi BR, Mazer D, Silveira LC, Jacinto CP, Di Sacco TH, Blanco $\mathrm{JH}$, et al. Physical exercise attenuates the cardiac autonomic deficit induced by nitric oxide synthesis blockade. Arq Bras Cardiol 2009; 92: 31-38, doi: 10.1590/S0066-782X 2009000100006.

10. Casonatto J, Polito MD. Aerobic post-exercise hypotension: a systematic review. Rev Bras Med Esporte 2009; 15: 151-157, doi: 10.1590/S1517-86922009000200014.
In conclusion, this study demonstrated that vascular reactivity participated in the differential blood pressure response in relation to exercise intensity.

\section{Acknowledgments}

The authors thank CAPES, CNPq and FAPESQ-PB for their financial support and UFPB for structural support.

11. Keese F, Farinatti P, Pescatello L, Cunha FA, Monteiro WD. Aerobic exercise intensity influences hypotension following concurrent exercise sessions. Int J Sports Med 2012; 33: 148-153.

12. Keese F, Farinatti P, Pescatello L, Monteiro W. A comparison of the immediate effects of resistance, aerobic, and concurrent exercise on postexercise hypotension. J Strength Cond Res 2011; 25: 1429-1436, doi: 10.1519/JSC.0b013e 3181d6d968.

13. Bermudes AM, Vassallo DV, Vasquez EC, Lima EG. Ambulatory blood pressure monitoring in normotensive individuals undergoing two single exercise sessions: resistive exercise training and aerobic exercise training. Arq Bras Cardiol 2004; 82: 65-64, doi: 10.1590/S0066-782X2004000100006.

14. Collier SR, Diggle MD, Heffernan KS, Kelly EE, Tobin MM, Fernhall B. Changes in arterial distensibility and flowmediated dilation after acute resistance vs. aerobic exercise. J Strength Cond Res 2010; 24: 2846-2852, doi: 10.1519/ JSC.0b013e3181e840e0.

15. Gomes Anunciacao P., Doederlein Polito M. A review on post-exercise hypotension in hypertensive individuals. Arq Bras Cardiol 2011; 96: e100-e109.

16. Forjaz CLM, Rezk CC, Cardoso CG Jr, Tinucci T. Resistance training and cardiovascular system. In: Negrão CE, Barretto ACP (Editors), Exercise cardiology: the athlete's cardiac. São Paulo: Manole; 2006. p 272-285.

17. Pescatello LS, Guidry MA, Blanchard BE, Kerr A, Taylor AL, Johnson AN, et al. Exercise intensity alters postexercise hypotension. J Hypertens 2004; 22: 1881-1888, doi: 10.1097/ 00004872-200410000-00009.

18. American College of Sports Medicine. ACSM's Guidelines for exercise testing and prescription. 7th edn. Baltimore: Lippincott Williams and Wilkins; 2006.

19. Santana HA, Moreira SR, Neto WB, Silva CB, Sales MM, Oliveira $\mathrm{VN}$, et al. The higher exercise intensity and the presence of allele I of ACE gene elicit a higher post-exercise blood pressure reduction and nitric oxide release in elderly women: an experimental study. BMC Cardiovasc Disord 2011; 11: 71, doi: 10.1186/1471-2261-11-71.

20. Seifi-Skishahr F, Siahkohian M, Nakhostin-Roohi B. Influence of aerobic exercise at high and moderate intensities on lipid peroxidation in untrained men. J Sports Med Phys Fitness 2008; 48: 515-521.

21. Gobatto CA, de Mello MA, Sibuya CY, de Azevedo Jr, dos Santos LA, Kokubun E. Maximal lactate steady state in rats submitted to swimming exercise. Comp Biochem Physiol A Mol Integr Physiol 2001; 130: 21-27, doi: 10.1016/S1095-6433(01) 00362-2. 
22. Bruner CA, Vargas I. The activity of rats in a swimming situation as a function of water temperature. Physiol Behav 1994; 55: 21-28, doi: 10.1016/0031-9384(94)90004-3.

23. Marti J, Armario A. Effects of diazepam and desipramine in the forced swimming test: influence of previous experience with the situation. Eur J Pharmacol 1993; 236: 295-299.

24. Engel PC, Jones JB. Causes and elimination of erratic blanks in enzymatic metabolite assays involving the use of $N A D+$ in alkaline hydrazine buffers: improved conditions for the assay of L-glutamate, L-lactate, and other metabolites. Anal Biochem 1978; 88: 475-484, doi: 10.1016/0003-2697 (78)90447-5.

25. Furchgott RF, Zawadzki JV. The obligatory role of endothelial cells in the relaxation of arterial smooth muscle by acetylcholine. Nature 1980; 288: 373-376, doi: 10.1038/288 $373 \mathrm{a} 0$.

26. Ajay M, Gilani AU, Mustafa MR. Effects of flavonoids on vascular smooth muscle of the isolated rat thoracic aorta. Life Sci 2003; 74: 603-612, doi: 10.1016/j.Ifs.2003.06.039.

27. Bradford MM. A rapid and sensitive method for the quantitation of microgram quantities of protein utilizing the principle of protein-dye binding. Anal Biochem 1976; 72: 248-254, doi: 10.1016/0003-2697(76)90527-3.
28. Carr AJ, Hopkins WG, Gore CJ. Effects of acute alkalosis and acidosis on performance: a meta-analysis. Sports Med 2011; 41: 801-814, doi: 10.2165/11591440-000000000-00000.

29. Jen CJ, Chan HP, Chen HI. Acute exercise enhances vasorelaxation by modulating endothelial calcium signaling in rat aortas. Am J Physiol Heart Circ Physiol 2002; 282: H977-H982, doi: 10.1152/ajpheart.00693.2001.

30. Thioub S, Mansourati J, Corporeau C, Heylen E, Delarue J, Guerrero F. Effects of n-3 fatty acids and acute exercise on endothelium-dependent vasorelaxation in healthy rat aorta. Br J Nutr 2009; 101: 829-835.

31. Yang AL, Lo CW, Lee JT, Su CT. Enhancement of vasorelaxation in hypertension following high-intensity exercise. Chin J Physiol 2011; 54: 87-95.

32. Jendzjowsky NG, DeLorey DS. Short-term exercise training augments sympathetic vasoconstrictor responsiveness and endothelium-dependent vasodilation in resting skeletal muscle. Am J Physiol Regul Integr Comp Physiol 2012; 303: R332-R339, doi: 10.1152/ajpregu.00053.2012.

33. Casonatto J, Tinucci T, Dourado AC, Polito M. Cardiovascular and autonomic responses after exercise sessions with different intensities and durations. Clinics 2011; 66: 453-458, doi: 10.1590/S1807-59322011000300016. 